\title{
Distribuição e densidade do bivalve Anomalocardia brasiliana em praias do Rio Grande do Norte durante um período de pluviosidade atípica
}

\author{
Talita Pinheiro Belém * \\ Rodrigo Sávio Teixeira de Moura \\ Gustavo Gonzaga Henry-Silva \\ Departamento de Ciências Animais, Laboratório de Limnologia e Qualidade de Água do Semiárido \\ Universidade Federal Rural do Semi-Árido, CEP 59.625-900, Mossoró - RN, Brasil \\ * Autor para correspondência \\ talitapbelem@bol.com.br
}

Submetido em 03/05/2012

Aceito para publicação em 12/12/2012

\section{Resumo}

O presente trabalho teve como objetivo avaliar a distribuição e a densidade de Anomalocardia brasiliana em $22 \mathrm{~km}$ de praias da região oeste do Rio Grande do Norte, durante e após períodos de pluviosidade atípica relacionada com o fenômeno La Niña. Foram realizadas quatro coletas semestrais entre os meses de Abril/2009 e Outubro/2010, sendo realizados transcectos perpendiculares à linha da praia, ao longo de um gradiente espacial de distanciamento do estuário, visando coletar organismos, sedimento e dados sobre a temperatura e salinidade da água. Não foram constatadas diferenças significativas na densidade de $A$. brasiliana entre as diferentes épocas do ano, sendo que as densidades médias foram 218 ind. $/ \mathrm{m}^{2} \mathrm{em}$ Abril/2009, 198 ind./m² em Outubro/2009, 233 ind. $/ \mathrm{m}^{2}$ em Abril $/ 2010$ e 200 ind./m² em Outubro/2010. Anomalocardia brasiliana apresentou um padrão de distribuição bem definido, com sua ocorrência restrita principalmente à região estuarina do Rio Apodi/Mossoró, onde os teores de matéria orgânica do sedimento foram mais elevados. Pôde-se constatar que esta espécie apresentou reduzida resiliência, uma vez que não conseguiu retornar a sua densidade anterior a Março/2008, ou seja, antes das chuvas intensas ocasionadas pelo fenômeno La Niña.

Palavras-chave: Distribuição espacial; Estuário; La Niña; Matéria orgânica; Molusco

\section{Abstract}

Distribution and density of the bivalve Anomalocardia brasiliana in Rio Grande do Norte beaches during an atypical rainfall period. The aim of this study was to evaluate the distribution and density of Anomalocardia brasiliana along a $22 \mathrm{~km}$ stretch of beaches in the western region of Rio Grande do Norte during and after periods of unusual rainfall related to the La Niña phenomenon. Four samples were taken every six months between April 2009 and October 2010, where imaginary lines were made perpendicular to the beach, along a spatial gradient of distance from the estuary, to collect organisms, sediments and temperature and salinity water data. There were no significant differences in A. brasiliana density between the different seasons, and the average density was $218 \mathrm{ind} / \mathrm{m}^{2}$ in April 2009, $198 \mathrm{ind} / \mathrm{m}^{2}$ in October 2009, $233 \mathrm{ind} / \mathrm{m}^{2}$ in April 2010 and $200 \mathrm{ind} / \mathrm{m}^{2}$ in October 2010. A. brasiliana showed a well-defined pattern of distribution, with its occurrence 
restricted mainly to the Apodi/Mossoró River estuary, where the organic matter content of the sediment was higher. Thus, this species has low resilience, since it could not regain the density it displayed prior to March 2008, before the heavy rains caused by the La Niña phenomenon.

Key words: Estuary; La Niña; Organic matter; Shellfish; Spatial distribution

\section{Introdução}

Os moluscos bivalves estão entre os organismos que mais se destacam na pesca realizada pelas comunidades litorâneas, especialmente por serem facilmente coletados e por não necessitarem de instrumentos elaborados para a sua extração (BARREIRA; ARAUJO, 2005; DIAS et al., 2007). Dentre as principais espécies de moluscos capturadas no Brasil destaca-se Anomalocardia brasiliana (Gmelin, 1791). Este bivalve está amplamente distribuído ao longo de toda a costa brasileira, habitando áreas protegidas da ação de ondas e de correntes, ocorre tanto na faixa entremarés como no infralitoral raso em substrato lodoso ou areno-lodoso (NARCHI, 1972; RIOS, 1994; BOEHS; MAGALHÃES, 2004; RODRIGUES et al., 2010). Anomalocardia brasiliana por ser uma espécie eurialina e euritérmica pode ser considerada uma espécie rústica, possuindo ampla distribuição geográfica (ARAÚJO; NUNES, 2006; BOEHS et al., 2008; LIMA et al., 2009).

No nordeste brasileiro, esta espécie da família Veneridae é extraída do ambiente manualmente por meio de apetrechos rudimentares como pás e ancinhos (NISHIDA et al., 2006), sendo que suas conchas são muito utilizadas na produção de artesanato e como substituto da fração de brita que é adicionado na mistura do concreto (DIAS et al., 2007). Sua carne também é utilizada pelos pescadores como complementação da própria alimentação, sendo, muitas vezes, a única fonte de proteína animal na dieta dessas famílias (MCLACHLAN et al., 1995; BISPO et al., 2004; BARREIRA; ARAUJO, 2005; BOEHS et al., 2008).

Atualmente, os estoques de $A$. brasiliana estão sendo ameaçados, como vem ocorrendo no estado de Pernambuco e Rio Grande do Norte, onde a pesca desordenada pode comprometer as populações desta espécie (RODRIGUES, 2009; OLIVEIRA, 2010). No entanto, apesar da pesca intensa nestas regiões, ainda são escassos estudos ecológicos deste bivalve. Neste contexto, este trabalho objetivou compreender aspectos relacionados à distribuição e a densidade de $A$. brasiliana em praias da Costa Branca do Rio Grande do Norte, durante e após o fenômeno La Niña, no intuito de proporcionar informações ecológicas que possam auxiliar no manejo e na manutenção desse recurso pesqueiro.

\section{Materiais e Métodos}

As coletas foram realizadas na região litorânea oeste do Rio Grande do Norte, totalizando $22 \mathrm{~km} \mathrm{de}$ praias amostradas, tendo início na região estuarina do rio Apodi/Mossoró localizado no município de Grossos/ RN (X UTM = 706365,52; Y UTM = 9452115,41) (Figura 1). A região é denominada de Costa Branca, sendo o único lugar do Brasil em que a caatinga encontra o mar. Segundo a classificação climática de KöppenGeiger, a região apresenta um clima do tipo BSw'h', se caracterizando como um clima muito quente e semiárido (NASCIMENTO, 2004).

Foram realizadas quatro coletas semestrais, nos meses de Abril/2009, Outubro/2009, Abril/2010 e Outubro/2010, no período diurno e em marés baixas, totalizando dois anos de estudo. Cada coleta abrangeu uma faixa de aproximadamente $22 \mathrm{~km}$ de litoral, sendo feitos transcectos perpendiculares à linha da praia, ao longo da área de estudo. Cada transcecto teve $300 \mathrm{~m}$ de comprimento, em direção ao mar, sendo estes divididos em sete pontos, com um distanciamento de $50 \mathrm{~m}$ entre os pontos, sendo que cada um foi georreferenciado com auxílio de um GPS (Global Positioning System), utilizando a projeção UTM (Universal Transverse Mercator), zona 24S.

Em cada ponto foram obtidas amostras de sedimento com coletor circular de $10 \mathrm{~cm}$ de altura e de indivíduos de $A$. brasiliana, utilizando um coletor de 
FIGURA 1: Locais de coleta de A. brasiliana em $22 \mathrm{~km}$ de praias entre os municípios de Grossos e Tibau na região da Costa Branca no Rio Grande do Norte.

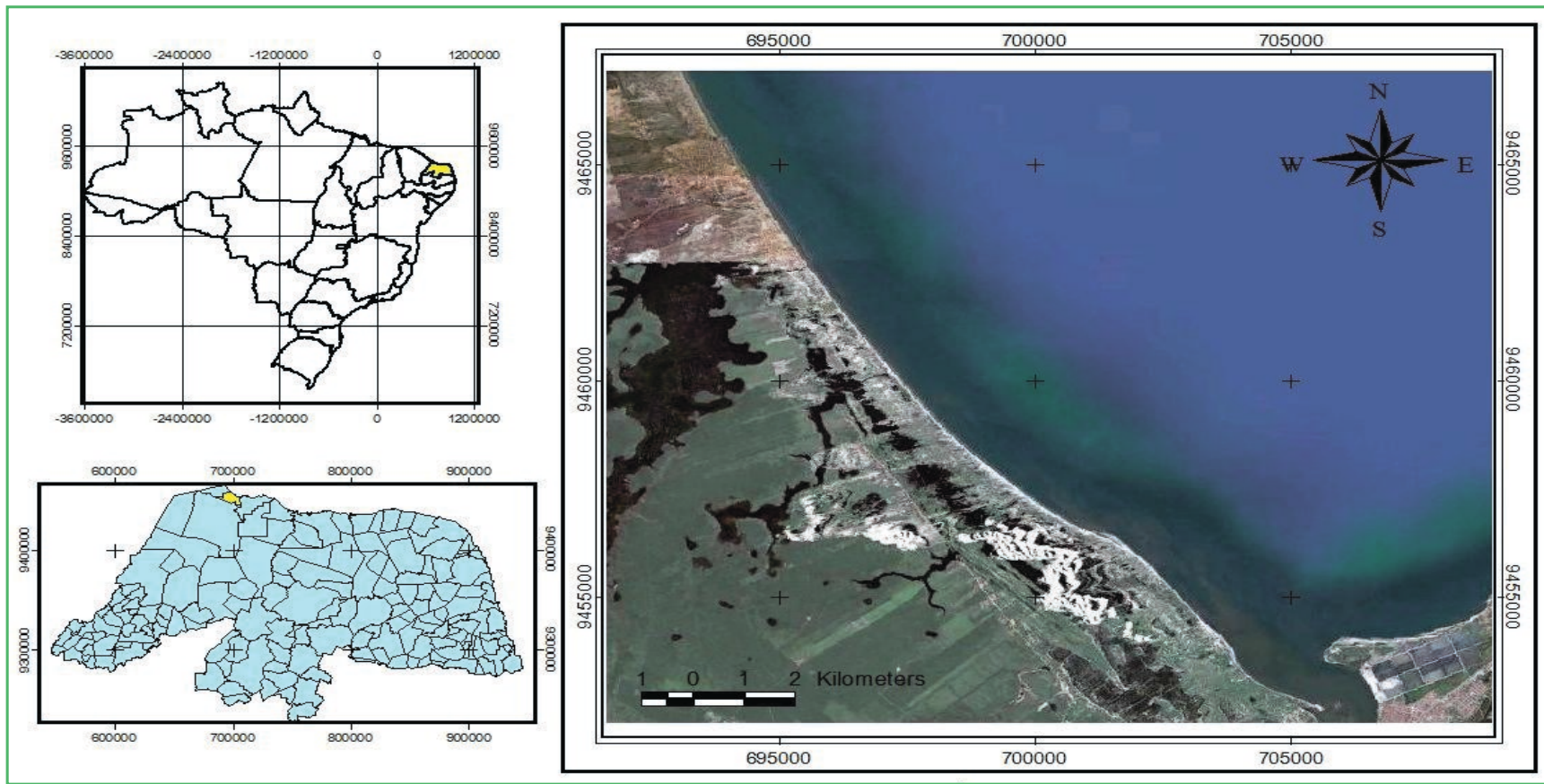

$0,019 \mathrm{~m}^{2}$ de área, as amostras foram armazenadas em sacos plásticos identificados para posterior análise em laboratório. Ainda in loco foram mensuradas variáveis abióticas, para cada transcecto, tais como temperatura e salinidade com auxílio de um multi-sensor e um refratômetro, respectivamente. Em laboratório foram realizadas a contagem e a lavagem do material biológico, com o auxílio de uma peneira de abertura de malha de $2 \mathrm{~mm}$. Para determinação do tamanho das conchas, foi utilizado um paquímetro de $0,05 \mathrm{~mm}$ de precisão. Os teores de matéria orgânica foram determinados pelo método gravimétrico (WETZEL; LIKENS, 1991).

Os dados de precipitação pluviométrica da região foram obtidos junto à Agência Nacional de Águas (ANA), utilizando a média aritmética de oito estações climatológicas distribuídas pela bacia hidrográfica do rio Apodi/Mossoró.

Foram produzidos mapas no intuito de verificar a extensão de ocorrência e a densidade de $A$. brasiliana, além de mapas para verificar as características de temperatura, salinidade e matéria orgânica na região estudada. Para a elaboração dos mapas foi capturada a imagem da área de estudo no formato JPG, pelo programa Google Earth (GOOGLE), em seguida realizada a transformação da imagem para o formato TIFF. Com o programa IMPIMA, contido no pacote SPRING 5.1, foi realizada a separação das bandas da imagem. Em seguida, foram feitos os registros das bandas 1, 2, 3 na cor verdadeira. Com o sistema de informações geográficas ArcView 3.2, foi realizada a interpolação dos dados espaciais, utilizando o método IDW (Inverse Distance Weighted), descrito por Mello et al. (2003), conforme a equação a seguir.

$$
X p=\frac{\sum_{i=1}^{N}\left(\frac{1}{d_{i}^{2}} \times X_{i}\right)}{\sum_{i=1}^{N}\left(\frac{1}{d_{i}^{2}}\right)}
$$

Onde:

Xp é o valor estimado

Xi é o valor do i-ésimo ponto amostrado

di é a distância euclidiana entre o i-ésimo ponto da vizinhança e o ponto amostrado

n é o número de amostras. 
Foram feitas análises de regressão linear simples para determinar quais fatores abióticos influenciam na distribuição e densidade de $A$. brasiliana, e o comportamento das variáveis abióticas e bióticas em relação à distância do estuário. $O$ teste não paramétrico de Kruskall-Wallis foi empregado para verificar a existência de diferenças significativas entre as densidades de $A$. brasiliana nas diferentes épocas. Identificada diferenças significativas foi aplicado o teste a posteriori de Student-Newman-Keuls. O nível de significância utilizado foi de $5 \%$.

\section{Resultados}

Nos anos de 2008 e 2009, a precipitação pluviométrica foi elevada devido ao fenômeno La Niña que tende a causar chuvas acima da média sobre a região semiárida do Nordeste brasileiro. Neste período foram observadas chuvas em todos os meses, exceto de setembro a novembro, com uma precipitação anual de $1185 \mathrm{~mm}$ em toda a bacia hidrográfica do Rio Apodi/ Mossoró. A maior precipitação ocorreu nos quatro meses que antecedem a coleta de Abril/2009 (776 mm). Já nos seis meses que antecederam a segunda coleta (Outubro/2009), ocorreu uma precipitação de 409 mm, sendo que em setembro e outubro não foram registradas precipitações. No ano de 2010, a precipitação anual foi reduzida, com um total acumulado de $525 \mathrm{~mm}$, porém
$84 \%$ da precipitação anual ocorreram nos primeiros períodos do ano, com o valor máximo em abril de 2010 (212 mm) (Figura 2).

Os menores valores de salinidade na área de ocorrência de $A$. brasiliana foram constatados em Abril/2009, com um valor médio de nove e os maiores valores em Outubro/2009, apresentando o valor médio de 42. Em Abril/2010 e Outubro/2010 o valor médio foi de 39 em ambos os meses (Figura 3A). A temperatura média para os quatro períodos na área de ocorrência de $A$. brasilina foi de $31^{\circ} \mathrm{C}$. O mês de Abril/2009 apresentou as maiores temperaturas, com um valor médio de $33^{\circ} \mathrm{C}$. Enquanto, em Abril/2010 foi encontrada a menor temperatura média $\left(29,8^{\circ} \mathrm{C}\right)$. Em Outubro/2009 e Outubro/2010 os valores médios foram $31,5^{\circ} \mathrm{C}$ e $31,9^{\circ} \mathrm{C}$, respectivamente (Figura 3B). A maior porcentagem média de matéria orgânica foi observada em Outubro/2009 (4,7 \%). Em Abril/2010 e Outubro/2010 os valores médios foram gradativamente reduzindo em relação aos demais períodos, atingindo os valores médios de 3,6 e 3,1\%, respectivamente (Figura 3C).

A densidade média de $A$. brasiliana, nos pontos de ocorrência, em Abril $/ 2009$ foi de 218 ind. $/ \mathrm{m}^{2}$. Em Outubro/2009 à densidade média foi de $198 \mathrm{ind} . / \mathrm{m}^{2}$, enquanto que em Abril $/ 2010$ foi de 233 ind. $/ \mathrm{m}^{2}$. Em Outubro/2010 a densidade média foi de 200 ind. $/ \mathrm{m}^{2}$. Não foram constatadas diferenças significativas na

FIGURA 2: Precipitação média (mm) da Bacia Hidrográfica do rio Apodi/Mossoró de outubro/2007 a outubro/2010 (Fonte: Agência Nacional de Águas/ANA - 2007/2010)

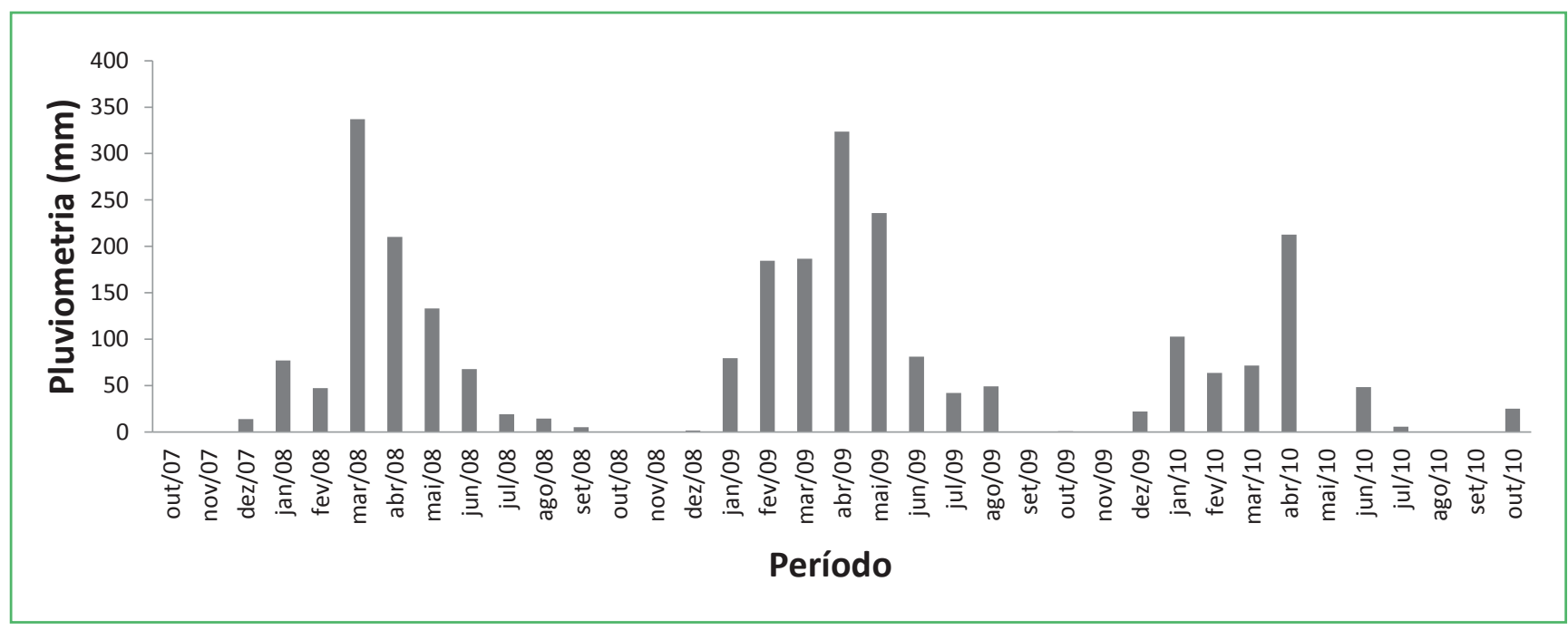


FIGURA 3: Médias e desvio padrão das variáveis abióticas na área de ocorrência de A. brasiliana, nas diferentes épocas do ano. A) Salinidade; B) Temperatura; C) \% de Matéria Orgânica.
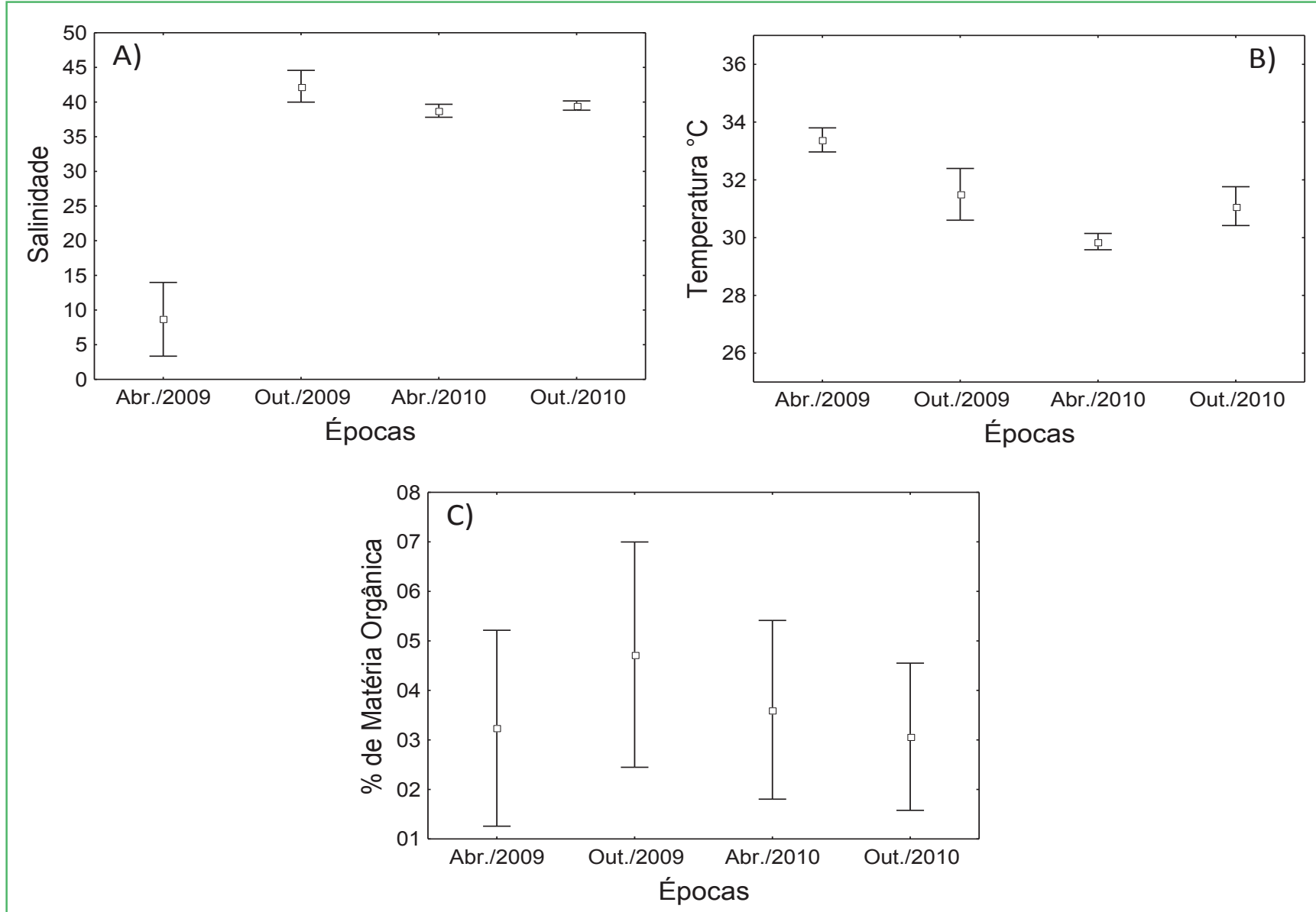

densidade de $A$. brasiliana entre as diferentes épocas do ano (Figura 4).

Relacionando a densidade média de $A$. brasiliana com a salinidade, observou-se para as quatro épocas que apenas em Abril/2010 não houve uma correlação significativa ( $\alpha=5 \%$ ). O mês de Abril nos anos de 2009 apresentou uma correlação negativa, enquanto o mês de Outubro de ambos os anos apresentou uma correlação positiva (Figura 5). A análise de regressão entre a densidade média de $A$. brasiliana com a porcentagem de matéria orgânica revelou que para as quatro épocas houve uma correlação significativa $(\alpha=5 \%)$ e positiva, indicando assim que a abundância de $A$. brasiliana está diretamente relacionada com a matéria orgânica. Os meses de Abril nos ano de 2009 e 2010 apresentaram as maiores correlações, com os valores de $\mathrm{R}^{2}$ igual a 0,45 e 0,37 (Figura 6).
FIGURA 4: Média da densidade dos pontos de ocorrência de $A$. brasiliana o desvio padrão nas diferentes épocas do ano.

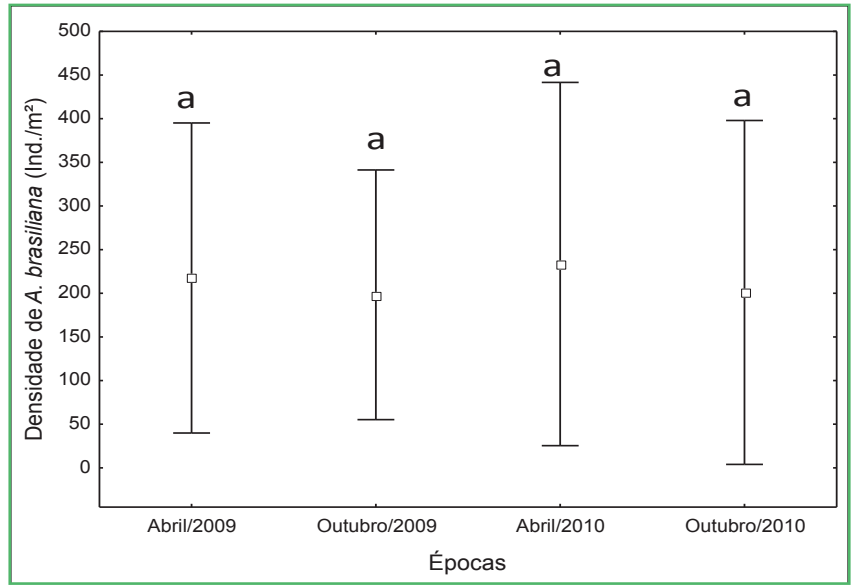

Observou-se que Abril de 2009 foi o único período que apresentou uma correlação positiva entre a salinidade 
FIGURA 5: Regressão da densidade média de A. brasiliana com os valores de salinidade.

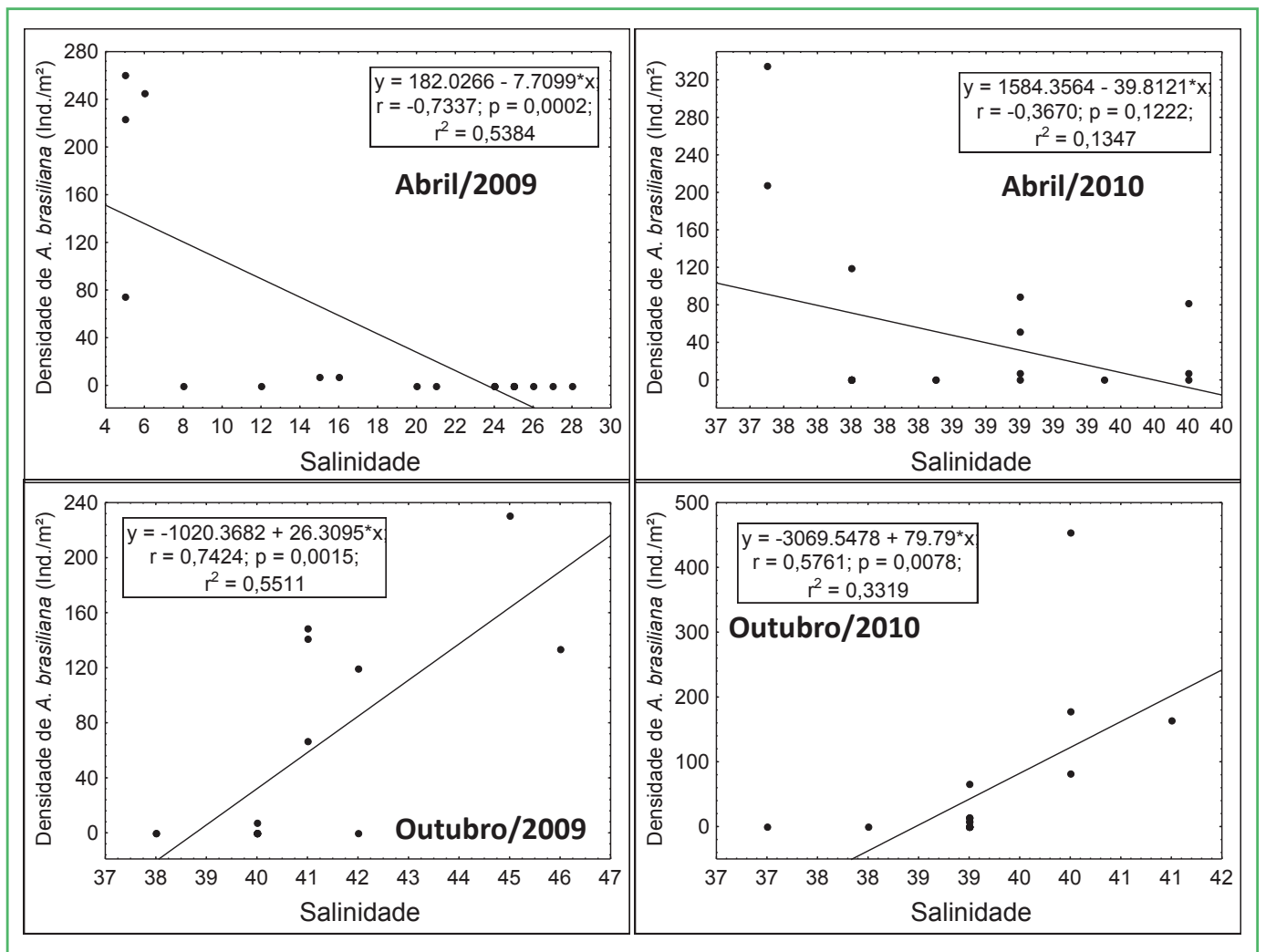

FIGURA 6: Regressão da densidade média de A. brasiliana com a \% porcentagem de matéria orgânica.

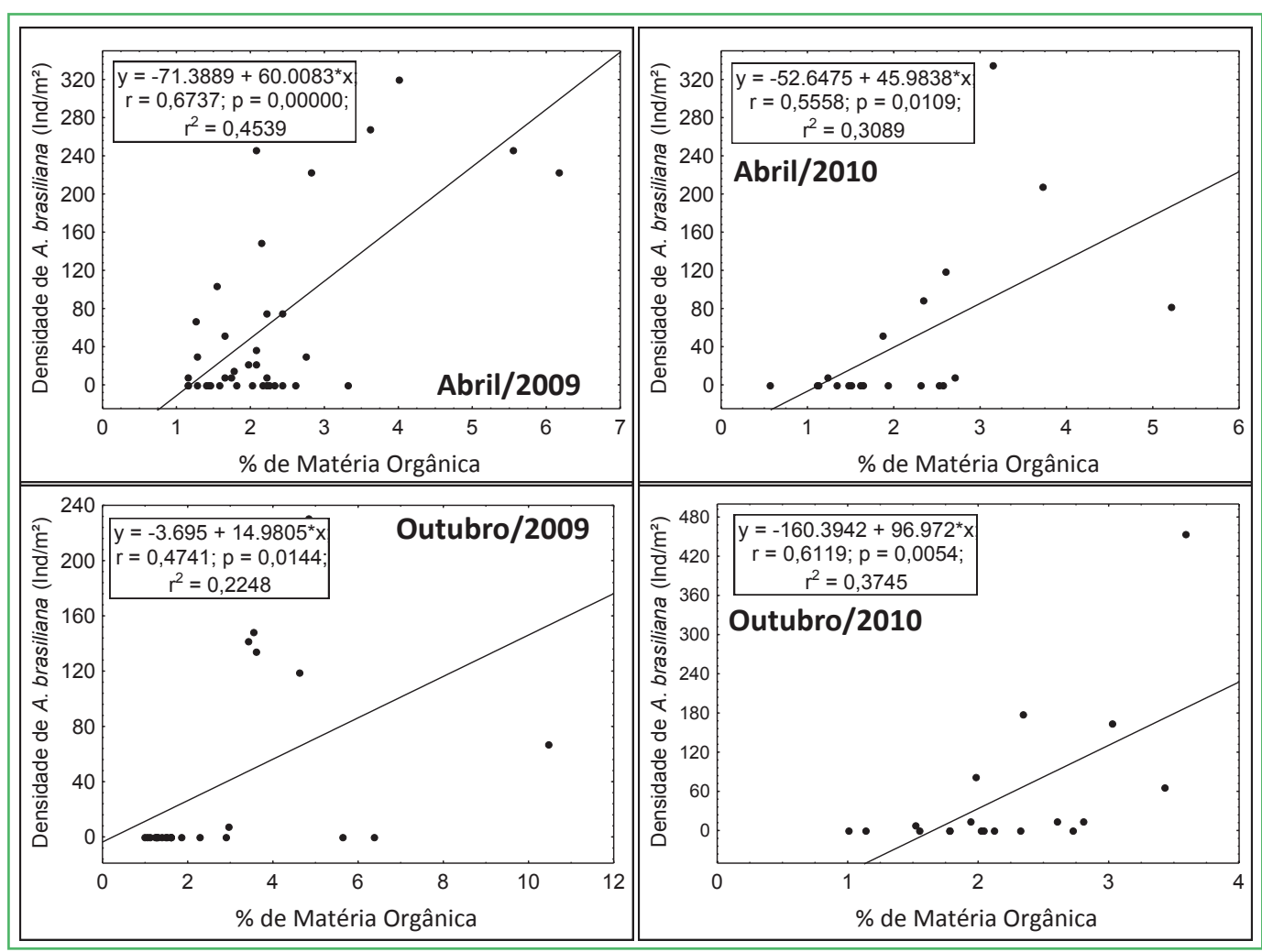


e a distância do estuário $\left(\mathrm{R}^{2}=0,4\right)$ (Figura 7). Entretanto em Outubro/2009, Abril/2010 e Outubro/2010 foram detectadas correlações negativas entre a salinidade e o afastamento do estuário do rio Apodi/Mossoró. Em Abril de 2009 e 2010 foram observados os menores valores de salinidade na região estuarina, sendo que estes valores reduzidos se estenderam até $2,9 \mathrm{~km}$ do estuário (Figura 8).

Verificou-se que em Abril de 2010 ocorreu uma correlação positiva $\left(\mathrm{R}^{2}=0,6\right)$ entre temperatura e distância do estuário (Figura 9). Para os demais períodos foram observados maiores valores de temperatura próximos à região estuarina. Constatou-se ainda há ausência de grandes amplitudes de variação desta variável ao longo da área de estudo (Figura 10).

Em todos os períodos analisados foram observadas correlações significativas e negativas entre porcentagem de matéria orgânica e a distância do estuário $(\mathrm{p} \leq 5 \%)$, sendo que os valores de $\mathrm{R}^{2}$ variaram de 0,222 a 0,380 (Figura 11). Analisando a variação espacial da matéria orgânica ao longo da área de estudo, observou-se, para os quatro períodos, maiores valores próximos a região estuarina. Em Outubro/2009 foi observada a maior porcentagem média de matéria orgânica em uma faixa de 2,9 km de extensão do estuário (Figura 12).

Analisando a distribuição espacial da densidade de $A$. brasiliana, constatou-se para os quatro períodos uma correlação negativa e significativa (Figura 13). Assim, à medida que se afasta do estuário, a densidade de $A$. brasiliana apresentou uma redução do número de indivíduos. Em Abril/2009 foi observada a ocorrência de $A$. brasiliana até a $6,2 \mathrm{~km}$ de distância do estuário, observando as maiores densidades entre os quilômetros 0,2 e 1,8 com valores médios de 226 ind. $/ \mathrm{m}^{2}$. Em Outubro/2009, observou-se a ocorrência de $A$. brasiliana em uma faixa de extensão de $2,2 \mathrm{~km}(0,2$ a 2,4 km), com a densidade média de 145 ind./m. Em Abril/2010 pôde-se observar a presença de duas manchas populacionais, a primeira até $2 \mathrm{~km}$ de distância do estuário, apresentando a densidade média de $140 \mathrm{ind} . / \mathrm{m}^{2}$, a segunda mancha a

FIGURA 7: Regressão dos valores de salinidade ao longo da área de estudo.

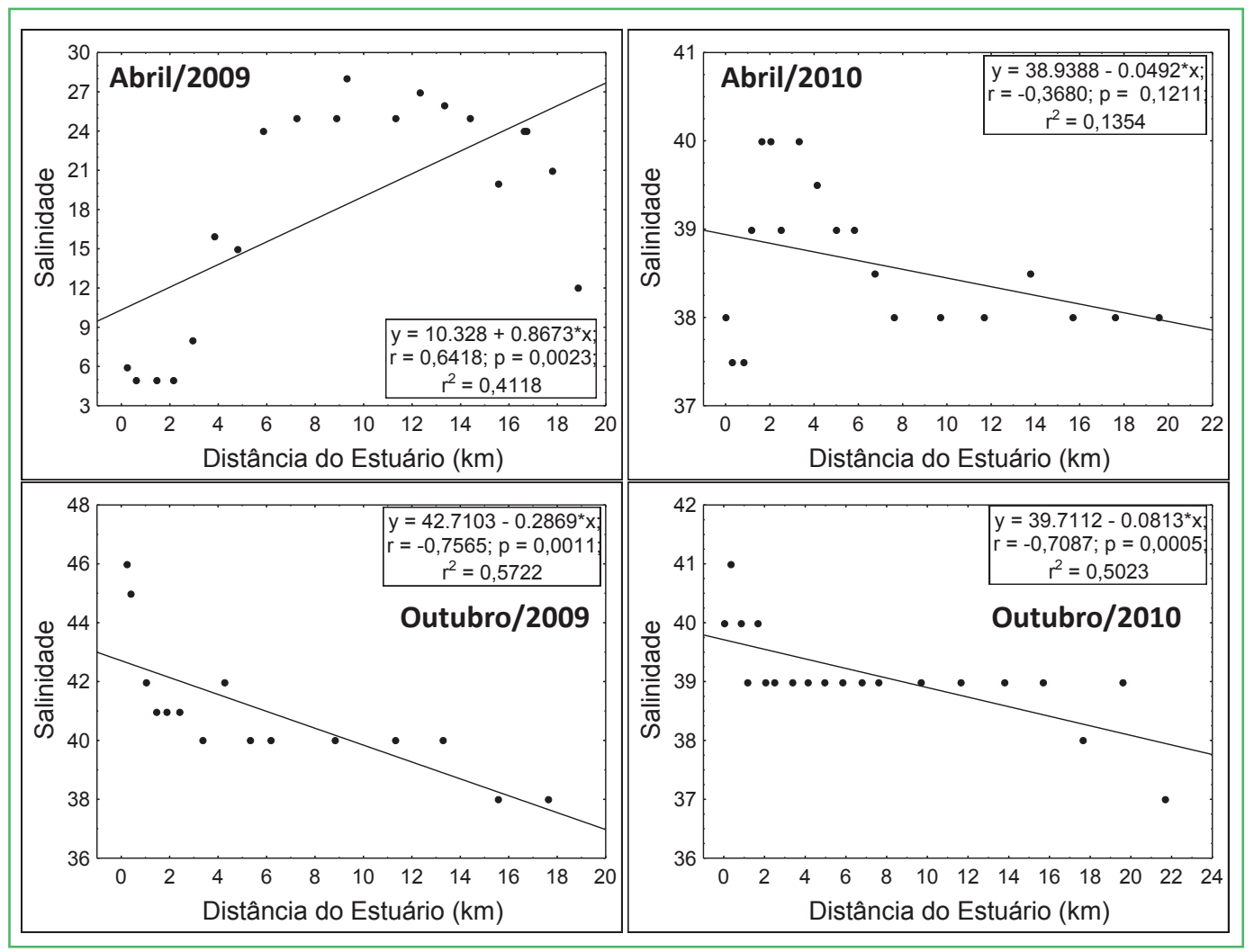


FIGURA 8: Mapa de distribuição potencial de salinidade.

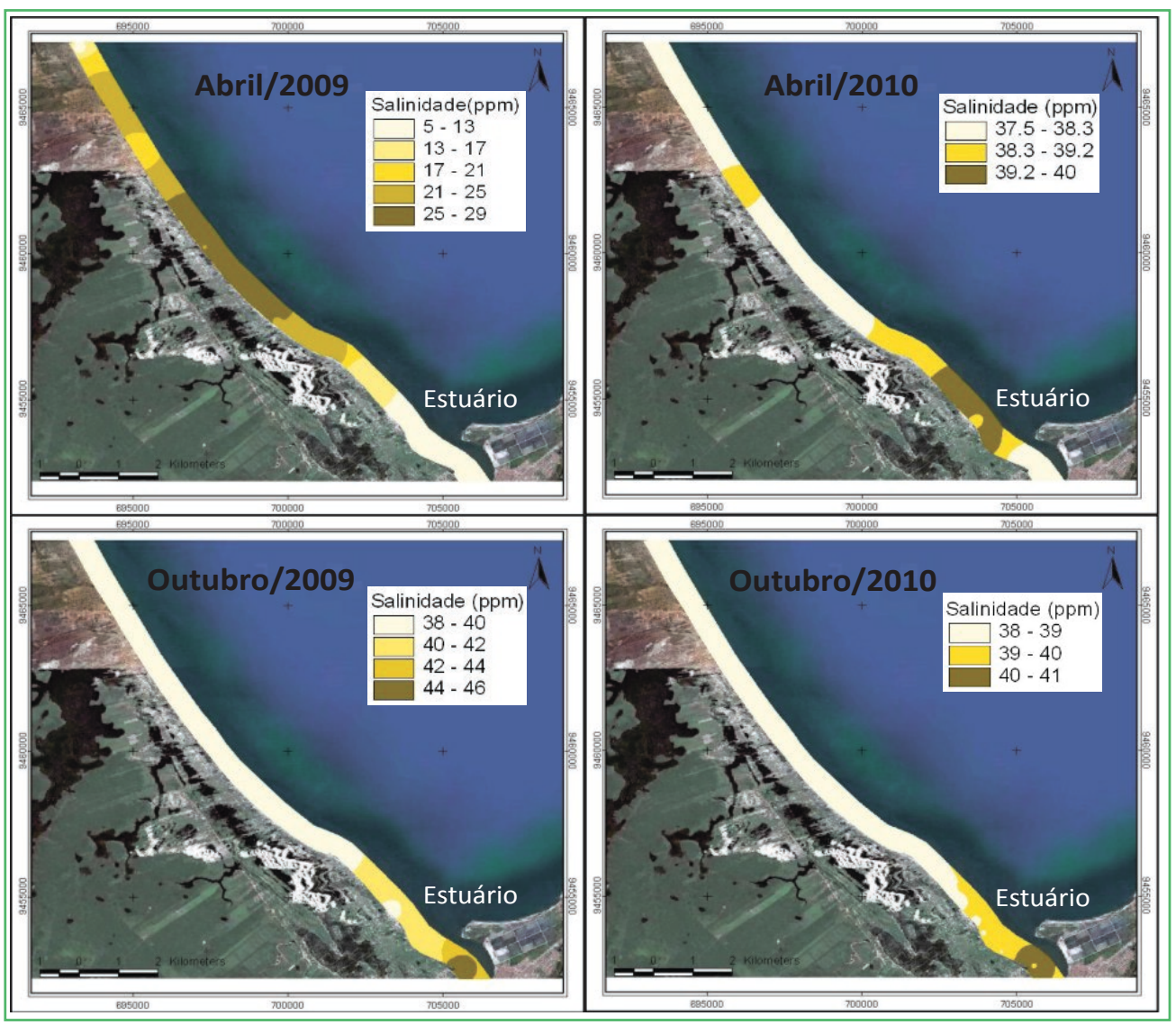

FIGURA 9: Regressão dos valores de temperatura ao longo da área de estudo.
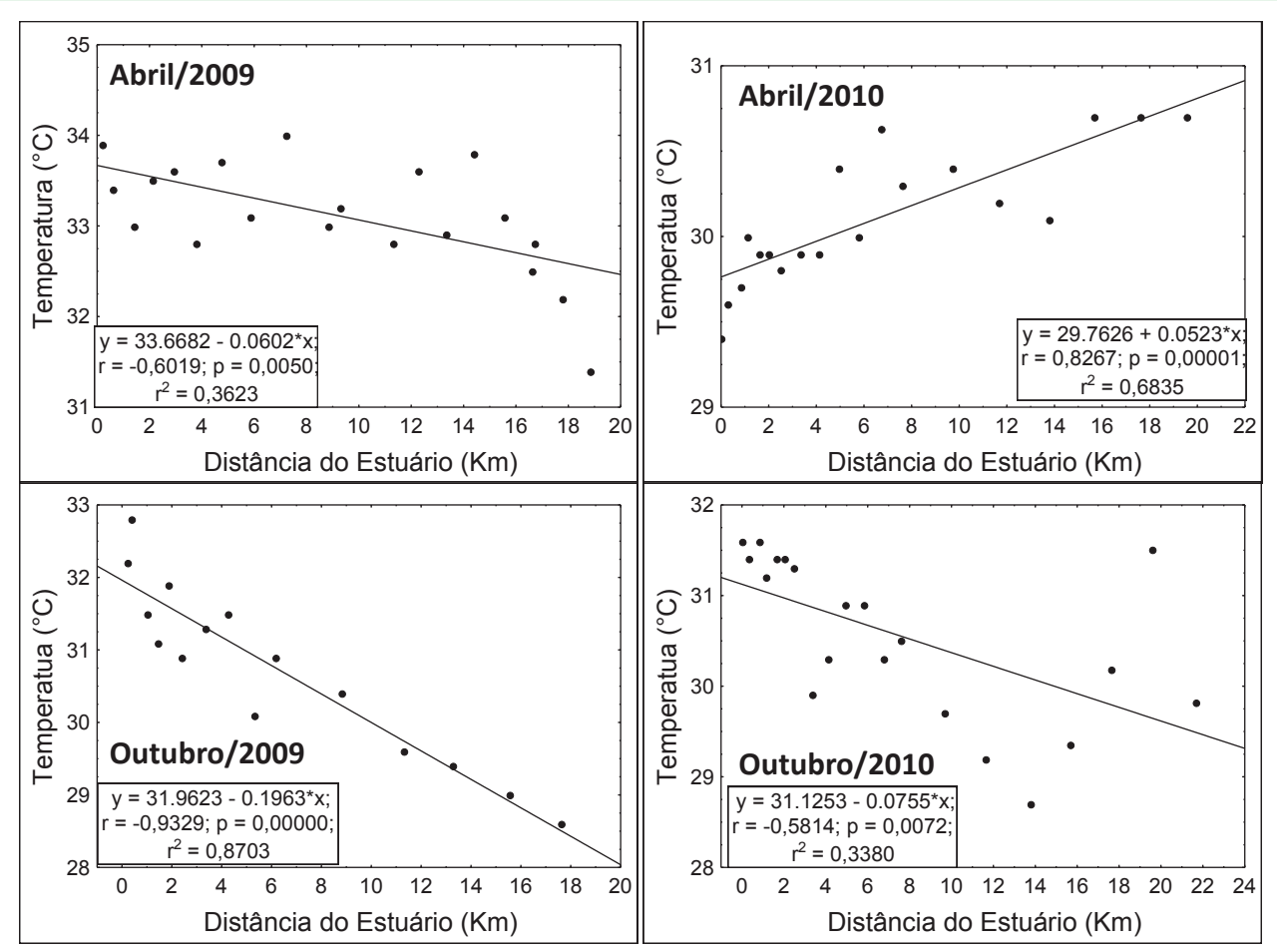
FIGURA 10: Mapa de distribuição potencial de temperatura.

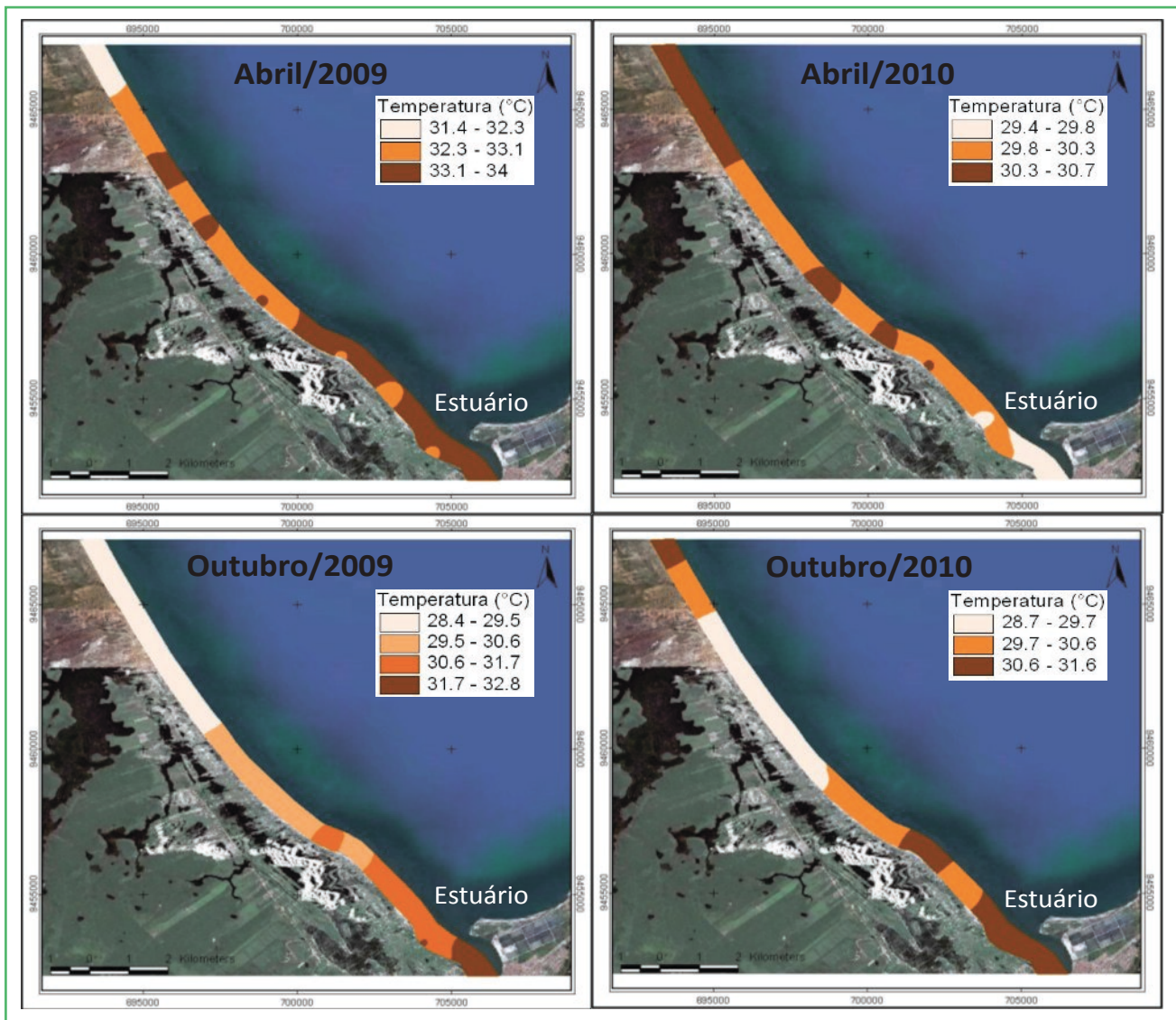

FIGURA 11: Regressão da porcentagem de matéria orgânica ao longo da área de estudo.

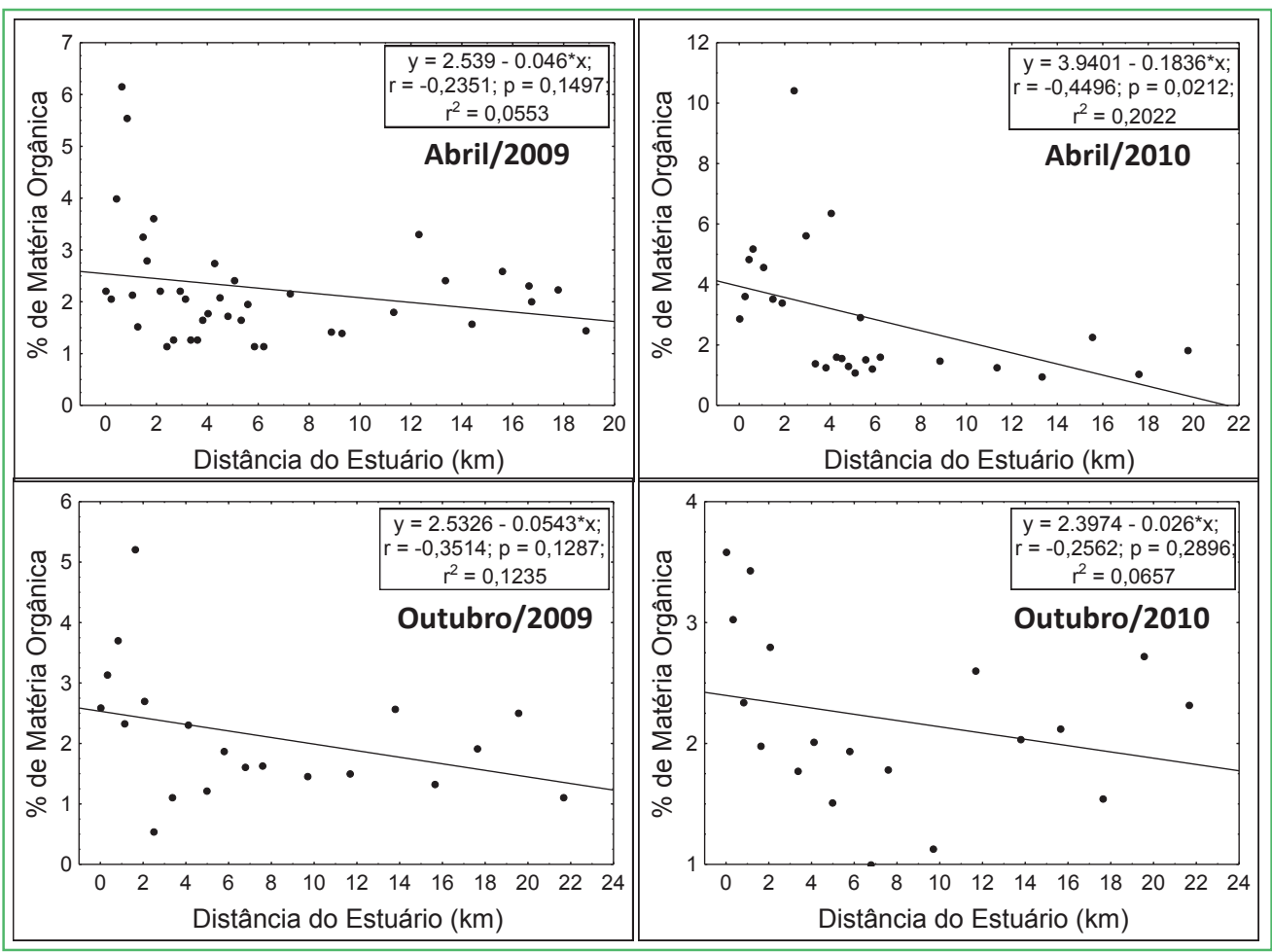


FIGURA 12: Mapa de distribuição potencial da \% de matéria orgânica.

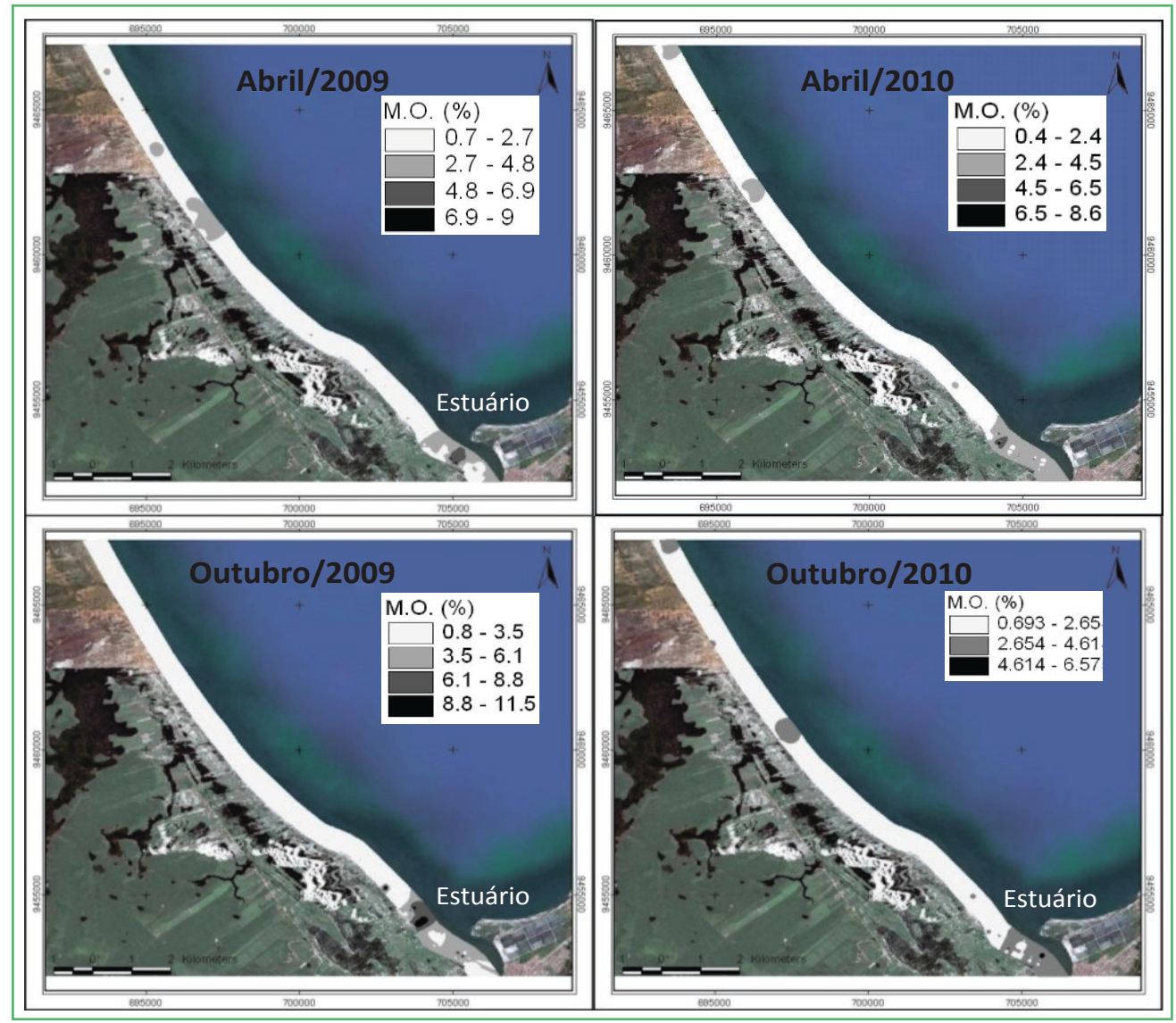

FIGURA 13: Regressão da densidade média de A. brasiliana ao longo da área de estudo.

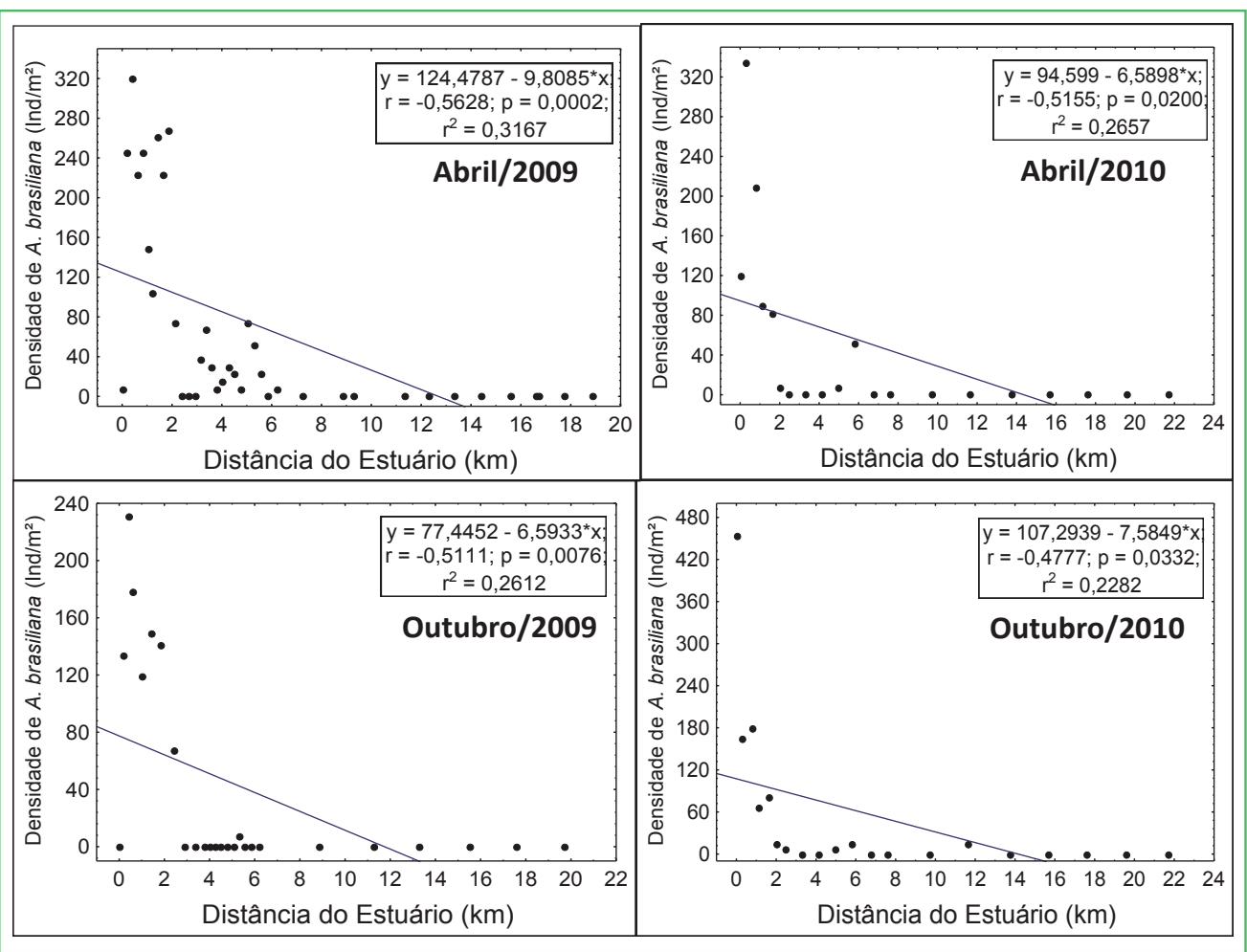


ocorreu entre os quilômetros 5 a 5,8, com a densidade média de 30 ind. $/ \mathrm{m}^{2}$. Em Outubro/2010 houve a presença de três manchas populacionais. A primeira mancha apresentou densidade média de 138 ind. $/ \mathrm{m}^{2}$, se estendendo até $2,5 \mathrm{~km}$ de distância do estuário. A segunda mancha ocorreu entre os quilômetros 5 e 5,8, com a densidade média de 11 ind. $/ \mathrm{m}^{2}$, já a terceira mancha apresentou densidade média de $14 \mathrm{ind} . / \mathrm{m}^{2}$, estando a 11,6km do estuário (Figura 14).
O molusco A. brasiliana, apresentou um tamanho máximo de $28 \mathrm{~mm}$, com o mínimo de $2 \mathrm{~mm}$. Em todas as épocas predominaram as classes de tamanho entre 20 a 25 $\mathrm{mm}$. Em quase todas as épocas (exceto em Outubro/2009) foi observada a ocorrência de indivíduos jovens (com os tamanhos entre 2 a $5 \mathrm{~mm}$ ). Em Abril/2009 apresentou uma porcentagem de $0,8 \%$ de indivíduos jovens, já em de Abril/2010 e Outubro/2010 a incidência de indivíduos jovens foi de 11 e $10 \%$, nos respectivos meses (Figura 15).

FIGURA 14: Mapa de distribuição potencial da densidade de A. brasiliana

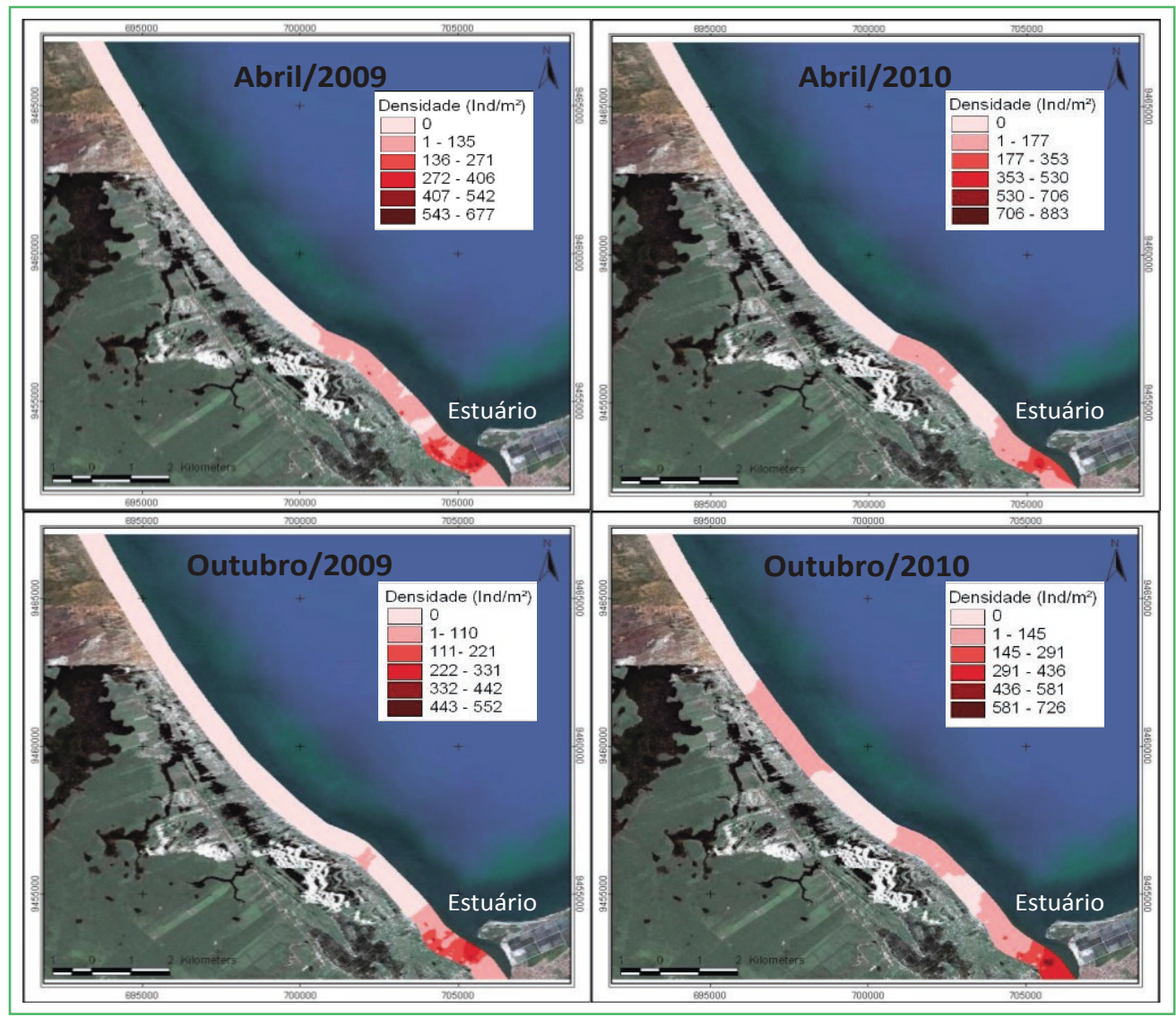

FIGURA 15: Histogramas das frequências de comprimentos (mm) de A. brasiliana.

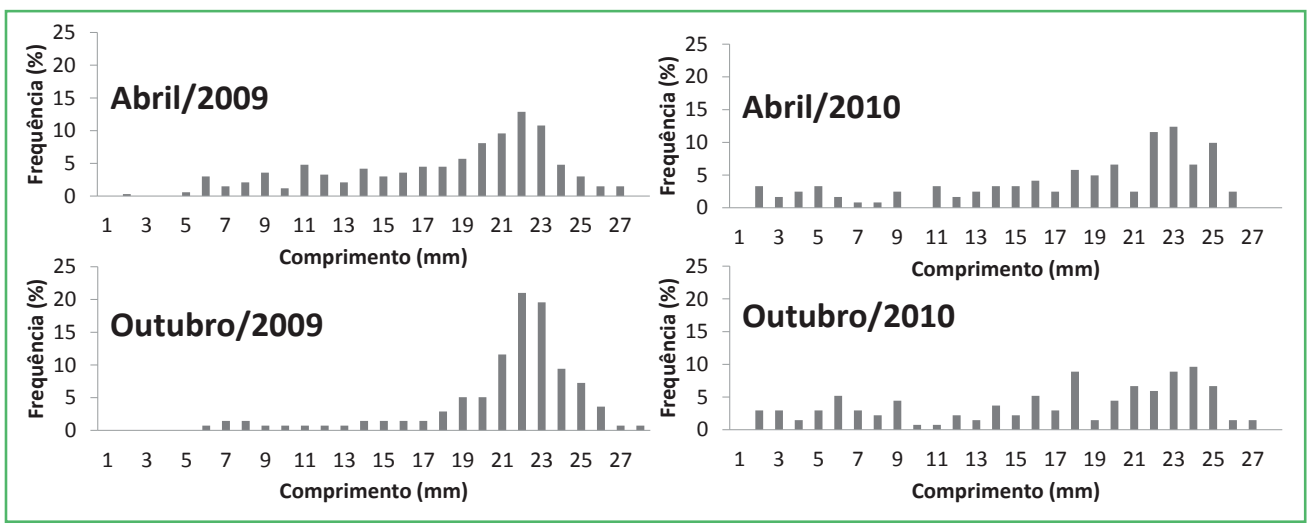




\section{Discussão}

A reduzida amplitude da variação da temperatura na área estudada e nas diferentes épocas do ano provavelmente está relacionada com a uniformidade climática da região, que é classificada como semiárida e muito quente (IDEMA, 2008). Barreira e Araújo (2005) em estudo sobre ciclo reprodutivo de $A$. brasiliana na praia do Canto da Barra-Fortim/CE, verificaram que esta espécie não sofreu influência significativa da temperatura. Schaeffer-Novelli $(1976 ; 1980)$ também não correlacionou a ocorrência de $A$. brasiliana com nenhum intervalo de temperatura em praias arenosas do litoral norte paulista. Provavelmente, a temperatura não foi uma variável importante para explicar a distribuição e a variação da densidade de $A$. brasiliana, visto que mesmo com a diminuição da temperatura da água em Abril/2010 na região estuarina, as densidades de $A$. brasiliana se mantiveram mais elevadas nesta região.

A salinidade, provavelmente, também não foi uma variável relevante para a distribuição espacial de A. brasiliana. Em Abril/2009 os menores valores de salinidade foram observados próximos a região estuarina do rio Apodi/Mossoró, em decorrência das chuvas intensas que ocorreram na bacia hidrográfica e que aportaram no estuário. No entanto, a diminuição da salinidade nesta região não foi suficiente para reduzir a densidade de $A$. brasiliana, que manteve um padrão de redução do número de indivíduos conforme se afasta do estuário. Já em Outubro/2009 e 2010 os valores de salinidade se elevaram na região estuarina, devido à ausência de chuvas e pelo aporte de água das salinas. Em praias mais afastadas da influência estuarina os valores de salinidade decaíram, assim como a densidade de $A$. brasiliana. Pode-se constatar que independente das pressões ambientais existentes na região, A. brasiliana possui sua maior densidade próxima ao estuário do rio Apodi-Mossoró. Leonel et al. (1983) demonstraram experimentalmente que $A$. brasiliana pode suportar variações salinas entre 17 e 42 , com ótimo em torno de 22. De fato, os resultados obtidos no presente estudo indicam que $A$. brasiliana apresentou capacidade de suportar elevadas variações de salinidade (valores médios 9 em Abril/2009 e de 42 em Outubro/2009).
Pôde-se observar que na região estuarina ocorreram as maiores concentrações de matéria orgânica no sedimento, provavelmente devido ao aporte de material particulado de toda a bacia hidrográfica do rio Apodi/Mossoró. Neste contexto, pode-se inferir que a disponibilidade de matéria orgânica pode ser mais importante do que a salinidade para a distribuição e manutenção das densidades de $A$. brasiliana. Este fato se justifica pela característica eurialina desta espécie, tolerando uma ampla variação da salinidade. É importante destacar, que as maiores densidades de $A$. brasiliana ocorreram na zona de influência do rio Apodi/ Mossoró, estando relacionadas positivamente com a porcentagem de matéria orgânica.

Monti et al. (1991) verificaram que o sucesso do recrutamento de indivíduos jovens está condicionado com a redução dos estoques adultos. É importante ressaltar que nos períodos que ocorreram as maiores frequências de indivíduos jovens, houve também uma redução de exemplares de tamanhos maiores. A não ocorrência de indivíduos jovens nos meses de Abril e Outubro do ano 2009 pode estar relacionada com o fato desses indivíduos não conseguirem resistir às variações de salinidade e o aporte de sedimento na região estuarina.

Durante o período de fevereiro a maio de 2009 foram registradas chuvas atípicas na região. Este fato provavelmente foi ocasionado pelo fenômeno climático La Niña gerado pelo resfriamento das águas do Oceano Pacífico Equatorial, que afetou a região entre 2008 e 2009, provocando um elevado índice pluviométrico em várias áreas do nordeste brasileiro. Um dos principais efeitos de episódios La Niña observados sobre o Brasil são as chuvas acima da média sobre a região semiárida do Nordeste do Brasil. No entanto, essas chuvas só ocorrem, se simultaneamente ao La Niña, as condições atmosféricas e oceânicas sobre o Oceano Atlântico mostrarem-se favoráveis, isto é, com a temperatura da superfície do mar (TSM) acima da média no Atlântico Tropical Sul e abaixo da média no Atlântico Tropical Norte (CÂMARA, 2011; CPTEC; INPE, 2012).

Rodrigues (2009), em estudo realizado na região estuarina do rio Apodi/Mossoró, verificou que a densidade média de A. brasiliana em Fevereiro/2008 foi de 900 ind. $/ \mathrm{m}^{2}$, sendo que em Maio/2008, quando 
se iniciaram as chuvas atípicas na região, a densidade média foi reduzida para 650 ind. $/ \mathrm{m}^{2}$. Esta redução provavelmente esteve relacionada à intensa precipitação que ocorreu em toda a bacia hidrográfica do rio Apodi/Mossoró no período de Março a Maio de 2008, acarretando a diminuição brusca da salinidade com valores abaixo de 10 e o aumento do aporte de sedimento na região estuarina. No presente trabalho, a densidade média de $A$. brasiliana variou de 233 ind. $/ \mathrm{m}^{2}$ a 198 ind./ $\mathrm{m}^{2}$. Neste contexto, pôde-se constar que as populações desta espécie apresentaram reduzida resiliência, uma vez que as mesmas não conseguiram retornar a sua densidade anterior a Março/2008 (900 ind. $\left./ \mathrm{m}^{2}\right)$, ou seja, antes das chuvas intensas ocasionadas pelo fenômeno La Niña. Estas chuvas atípicas que ocorreram em 2008 e 2009 na região atuaram como um agente perturbador na estruturação da densidade de $A$. brasiliana.

Pôde-se concluir, ainda que a quantidade de matéria orgânica influenciou na distribuição espacial de $A$. brasiliana, uma vez que a mesma está relacionada com a disponibilidade de alimento para estes moluscos filtradores. No presente estudo foi verificado que $A$. brasiliana apresentou um padrão de distribuição bem definido, com sua ocorrência restrita principalmente à região estuarina do Rio Apodi/Mossoró.

\section{Agradecimentos}

Ao CNPq e a ONG World Fisheries Trust pelo apoio financeiro para a realização do Projeto Gente da Maré. Os autores agradecem ainda aos estagiários e pós-graduandos do Laboratório de Limnologia e Qualidade de Água da Universidade Federal Rural do Semi-Árido (Limnoaqua) pelo apoio técnico e logístico nas atividades de campo.

\section{Referências}

ARAÚJO, C. M. Y.; NUNES, C. G. A guideline to molluscan bivalve reproductivestudies in brazilian marine management areas. In: INTERNATIONAL COASTAL SYMPOSIUM, 8, 2006, Itajaí. Proccedings... Itajaí: Coastal Education \& Research Foundation, 2006. p. 945-948.

BARREIRA, C. A. R.; ARAÚJO, M. L. R. Ciclo reprodutivo de Anomalocardia brasiliana (GMELIN, 1791) (Mollusca, Bivalvia, Veneridae) na praia do Canto da Barra, Fortim, Ceará, Brasil.
Boletim do Instituto de Pesca, São Paulo, v. 31, n. 1, p. 9-20, 2005.

BISPO, E. S.; SANTANA, L. R. R.; CARVALHO, R. D. S.; LEITE, C. C.; LIMA, M. A. C. Processamento, estabilidade e aceitabilidade de marinado de vongole (Anomalocardia brasiliana). Ciência e Tecnologia de Alimentos, Campinas, v. 24, n. 3, p. 353-356, 2004. BOEHS, G.; ABSHER, T. M.; CRUZ-KALED, A. C. Ecologia populacional de Anomalocardia brasiliana (Gmelin, 1791) (Bivalvia, Veneridae) na Baía de Paranaguá, Paraná, Brasil. Boletim do Instituto de Pesca, São Paulo, v. 34, n. 2, p. 259-270, 2008.

BOEHS, G.; MAGALHÃES, A. R. M. Simbiontes associados com Anomalocardia brasiliana (Gmelin) (Mollusca, Bivalvia, Veneridae) na Ilha de Santa Catarina e região continental adjacente, Santa Catarina, Brasil. Revista Brasileira de Zoologia, Curitiba, v. 21, n. 4, p. 865-869, 2004.

CÂMARA, F. R. A. Relação ecológica entre as comunidades fitoplanctônica e zooplanctônica em reservatório eutrofizado durante período de pluviosidade atípica. 2011. 134 f. Tese (Doutorado em Ecologia e Recursos Naturais) - Universidade Federal de São Carlos, São Carlos. 2011.

CPTEC - CENTRO DE PREVISÃO DE TEMPO E ESTUDOS CLIMÁTICOS; INPE - INSTITUTO NACIONAL DE PESQUISAS ESPACIAIS. Disponível em: <http://www.cptec. inpe.br>. Acesso em: 8 fev. 2012.

DIAS, T. L. P.; ROSA, R. S.; DAMASCENO, L. C. P. Aspectos socioeconômicos, percepção ambiental e perspectivas das mulheres marisqueiras da Reserva de Desenvolvimento Sustentável Ponta do Tubarão (Rio Grande do Norte, Brasil). Gaia Scientia, João Pessoa, v. 1, n. 1, p. 25-35, 2007.

IDEMA - INSTITUTO DE DESENVOLVIMENTO SUSTENTÁVEL E MEIO AMBIENTE DO RIO GRANDE DO NORTE. Perfil do seu município: Tibau. Disponível em: $<$ http:// www.idema.rn.gov.br/contentproducao/aplicacao/idema/socio economicos/arquivos/Perfil\%202008/Tibau.pdf>. Acesso em: $1 \overline{0}$ set. 2011.

LEONEL, R. M. V.; MAGALHÃES, A. R. M.; LUNETTA, J. E. Sobrevivência de Anomalocardia brasiliana (Gmelin, 1791) (Mollusca: Bivalvia), em diferentes salinidades. Boletim de Fisiologia Animal, Universidade de São Paulo, São Paulo, v. 7, p. 63-72, 1983.

LIMA, M. A.; SOARES, M. O.; PAIVA, C. C.; OSÓRIO, F. M.; PORFÍRIO, A. F.; MATTHEWS-CASCON, H. Osmorregulação em moluscos: o caso do bivalve estuarino tropical Anomalocardia brasiliana (Mollusca: Bivalvia). Conexões - Ciência e Tecnologia, Fortaleza, v. 5, n. 3, p. 79-84, 2009.

MCLACHLAN, A.; JARAMILLO, E.; DEFEO, O.; DUGAN, J.; RUYCK, A.; COETZEE, P. Adaptations of bivalves to different beach types. Journal of Experimental Marine Biology and Ecology, Amsterdam, v. 187, p. 147-160, 1995.

MELlO, C. R.; LIMA J. M.; SILVA, A. M.; MELLO, J. M.; OLIVEIRA, M. S. Krigagem e inverso do quadrado da distância para interpolação da equação de chuvas intensas. Revista Brasileira de Ciência do Solo, Viçosa, v. 27, p. 925-933, 2003.

MONTI, D.; FRENKIEL, L.; MOUËZA, M. Demography and growth of Anomalocardia brasiliana (Gmelin) (Bivalvia, Veneridae) in a mangrove, in Guadeloupe (French West Indies). Journal of Molluscan Studies, London, v. 57, p. 249-257, 1991. 
NASCIMENTO, S. R. Geoprocessamento aplicado à gestão de informações territoriais do município de Grossos-RN estudo multitemporal do uso e ocupação do solo. 2004. 98 f. Dissertação (Mestrado em Geociência) - Universidade Federal do Rio Grande do Norte, Natal. 2004.

NARCHI, W. Comparative study of the functional morphology of Anomalocardia brasiliana (GMELIN, 1791) and Tivela mactroides (born, 1778) (Bivalvia, Veneridae). Bulletin of Marine Science, Miami, v. 22, n. 3, p. 663-670, 1972.

NISHIDA, A. K.; NORDI, N.; ALVES, R. R. N. Mollusc gathering in Northeast Brazil: an ethnoecological approach. Human Ecology, Ithaca, v. 34, n. 1, p. 133-145, 2006.

OLIVEIRA, I. B. Estudo da estrutura populacional do marisco Anomalocardia brasiliana (Gmelin, 1791) na praia de Mangue Seco, litoral norte de Pernambuco-Brasil. 2010. 87 f. Dissertação (Mestrado em Recursos Pesqueiros e Aquicultura) - Universidade Federal Rural de Pernambuco, Recife. 2010.

RIOS, E. C. Coastal brazilian shells. Rio Grande: Fundação Cidade do Rio Grande, 1994. 255 p.
RODRIGUES, A. M. L. Ecologia populacional do molusco bivalve Anomalocardia brasiliana (Gmelin, 1791) (Bivalvia, Veneridae) em praias da região estuarina do rio Apodi/Mossoró-RN. 2009. 94 f. Dissertação (Mestrado em Ciência Animal) - Universidade Federal Rural do Semi-Arido, Mossoró. 2009.

RODRIGUES, A. M. L.; AZEVEDO, C. B.; SILVA, G. H. G. Aspectos da biologia e ecologia do molusco bivalve Anomalocardia brasiliana (Gmelin, 1791) (Veneridae). Revista Brasileira de Biociências, Porto Alegre, v. 8, n. 4, p. 377-383, 2010.

SCHAEFFER-NOVELLI, Y. Alguns aspectos ecológicos e análise populacional de Anomalocardia brasiliana (Gmelin, 1791) (Mollusca: Bivalvia), na praia do Saco da Ribeira, Ubatuba, Estado de São Paulo. 1976. 110 f. Tese (Doutorado em Zoologia) - Universidade de São Paulo, São Paulo. 1976.

SCHAEFFER-NOVELLI, Y. Análise populacional de Anomalocardia brasiliana (Gmelin, 1791) (Mollusca: Bivalvia), na praia do Saco da Ribeira, Ubatuba, Estado de São Paulo. Boletim do Instituto Oceanografico, Sao Paulo, v. 29, n. 2, p. 351-355, 1980.

WETZEL, R. G; LIKENS, G. E. Limnological analisys. 2. ed. New York: Springer Verlag, 1991. 391 p. 